\title{
The Impact of COVID-19 on Human Resource Management Practices and Future Marketing
}

\author{
Stavros Kalogiannidis (Adjunct Lecturer) \\ Department of Regional and Cross Border Development \\ University of Western Macedonia, Greece \\ E-mail: stavroskalogiannidis@gmail.com
}

ORCiD: https://orcid.org/0000-0002-2337-5775

Received: November 26, 2020

doi:10.5296/ijim.v6i1.17994
Accepted: March 23, 2021

Published: April 10, 2021

URL: https://doi.org/10.5296/ijim.v6i1.17994

\begin{abstract}
The increased prevalence of COVID-19 has had severe implications on the well-being of most organization and professionals most especially in the field of human resource management and marketing. This study focused on establishing the impact of COVID-19 on different human resource practices and future marketing. It was established that the dynamics of work have greatly changed from the traditional way of working from the organization's premises to working remotely at home. Consequently, marketing has also shifted to different online platforms since physical contact with customers is currently prohibited to maintain social distancing one way of preventing coronavirus. These changes have been associated with different negative implications and some positives as some professionals find it more flexible and convenient to work remotely. To cope with the current changing times, an organization must adjust and adapt to the new emerging technologies of working remotely and consequently implement strategic policies and procedures towards maintaining a steady flow.
\end{abstract}

Keywords: Human Resource Management, Covid-19, Marketing, SARS-CoV-2 


\section{Introduction}

Most organizations across the world are facing numerous challenges created by COVID-19 and one of the most significant challenges is the increased uncertainty among most organizations most especially concerning human resource control and maintaining a higher customer base through marketing (Kalogiannidis \& Chatzitheodoridis, 2021). Most organization have laid off their workers and consequently lost their customers ever since COVID-19 was declared a global pandemic and this has greatly affected the profitability levels of such organizations mostly due to deterioration in efficiency and productivity of the human resource (Lauer et al., 2020). The main challenges of most organizations today are very diverse as they cut across different complex issues that include; climate change increased political instabilities in both developing and developed countries, and severe economic downturns (Inoue \& Todo, 2020). In the current dynamic world, the different organizational problems associated with marketing and human resource management greatly affect the ability of an organization to operate strategically and achieve sustainable growth. By posing a great threat to the sustainability of an organization, these challenges enable an organization to be highly responsive and consequently adaptive to effectively organize and manage or control its workforce (Atkeson, 2020).

Kalogiannidis (2020) indicates that since the outbreak of Coronavirus, various organizations have continuously faced a prime challenge of unparalleled proportions, which forces them to dive into and directly manage unprecedented territory as they change or alter their entire workforce in different departmental areas or fields in ways not seen before. According to Barro and Weng (2020), most heads of organizations have applied different technical, physical and socio-psychological ways to reduce their workforce as means of surviving in the current times or the coronavirus pandemic. The market of some products or services offered by most organizations has reduced globally hence most organizations continue to reduce their workforce in different areas such as in sales and marketing departments since it's the only way of lowering operational costs (Baldwin \& Weder, 2020). The COVID-19 pandemic has posed a great need for human resource managers to think of new methods of adapting to challenging times. Remote working is one of the new emerging methods that most organization are adopting as a way of maintaining smooth operations and quality services to clients (McKibbin \& Fernando, 2020).

According to Baldwin and Weder (2020), most managers are striving hard to help their workforce adapt to and consequently cope with radical changes occurring in the work and social environment. For example, initially, most of the employees used to spend a lot of time at the workplace or within the physical boundaries of their organizations but now have no other option but to quickly adjust to remote work environments during the coronavirus pandemic. However, working remotely is also associated with some challenges since most employees are unable to find alternative places of convenient work most especially when they cannot operate efficiently at their homes (Baert et al., 2020). This is because most alternative places such as internet cafes or libraries are also closed hence people are unable to hold small business meetings or quick management seminars. 


\subsection{Aims and Objectives of the Study}

This research paper was aimed at establishing the impact of COVID-19 on human resource management practices and future marketing. The paper was also based on different strategic objectives that included;

- To determine the negative and positive implications of COVID-19 in areas of HRM and marketing;

- To establish the most effective mechanisms to address the COVID-19 based challenges in areas of HRM and marketing;

\subsection{Research Questions}

- What are the negative and positive implications of COVID-19 in areas of HRM and marketing;

- What are the most effective mechanisms to address the COVID-19 based challenges in areas of HRM and marketing?

\subsection{Hypotheses}

$\mathbf{H}_{1}$. There is a significant relationship between COVID-19 and HRM practices.

$\mathbf{H}_{2}$. There is a significant relationship between COVID-19 and future marketing.

\subsection{Significance of the Study}

The final findings of this research study are of great significance to the areas of marketing and human resource management most especially concerning the current and future wellbeing of these areas. With the increased uncertainty in the HRM sector due to COVID-19, the study findings will provide new approaches and alternatives that can be used to cope with the "new normal" in this sector. The study findings will also help to predict the future dynamics of marketing about the current situation of COVID -19. The final results will also contribute to the existing knowledge concerning the general implication of the coronavirus pandemic (COVID-19) on the sectors of human resource management and marketing.

\section{Literature Review}

This section presents a review of past information about HRM, marketing and COVID-19 as extracted from different peer-reviewed studies or articles. The literature review majorly focuses on the different HRM challenges and opportunities associated with the era of COVID-19

\subsection{HRM Challenges and Opportunities in the Times of COVID-19}

Atkeson (2020) indicates that one of the major HRM challenges brought about by the COVID-19 pandemic is the difficulty encountered in adjusting new and current employees as well as coping with the drastically altered work conditions that involve changing to remote work environments or implementing new undesirable workplace policies and procedures to maintain social distancing which is one way of preventing coronavirus. 


\section{MInstitute ${ }^{\text {Mink }}$}

The P-E fit theory asserts that people are mostly attracted to and consequently selected by companies or organizations that have cultural traits, values, and work features similar to the beliefs, desires and values of these individuals (He \& Harris, 2020). In this case, most professionals or causal workers who are accepted in an organization where their P-E fit is maximized tend to flourish and consequently experience elevated levels of job satisfaction, commitment and overall individual wellbeing. However, research indicates that when the environment that supports the values and beliefs of the workplace is altered, the different benefits derived from such a working environment are all affected and both the organization and employee are left with no option but to derive new ways of re-establishing a cordial working relationship. Similarly, with COVID-19, most benefits derived from a normal working environment have been altered (Kalogiannidis, Chatzitheodoridis, \& Kontsas, 2020).

Accrsoing to McKibbin and Fernando (2020), one of the major sought desires within the P-E fit work relationships focuses on the fundamental objective of establishing strong relationships with the organizations and consequently striving for communion with fellow workmates and the employer. Throughout the whole process of recruitment, potential employees are always attracted to an organization based on this major or fundamental objective. But as most organizations adjust to new forms of working due to COVID-19, physical interactions are bound to reduce or permanently diminish hence the newfound P-E incongruence as a result of the pandemic could have a disastrous impact on the general productivity and wellbeing of the workforce and organization as a whole (He \& Harris, 2020).

Khudhair et al. (2020) indicate that even amidst new forms of operating organizations such as working remotely, some organization are not yet conversant with the best ways through which working remotely can be made more effective towards increasing the productivity of employees. Studies reveal that enhancing employee commitment through remote working and consequently maintaining a good working relationship between the employees and the organization requires implementation of strategic policies and procedures which sometimes is difficult to fulfil in some organization most especially in such times of COVID-19 where resources to support such initiatives are limited (Lauer et al., 2020; Stavros, Melfou, \& Papaevangelou, 2020).

\subsection{Marketing Challenges and Opportunities in the COVID-19 ERA}

Kalogiannidis, Chatzitheodoridis, and Kontsas (2020) indicate that the marketing sector has equality been affected by the dynamics of the coronavirus pandemic since most traditional marketing practices are no longer viable or effective with the "new normal." Research indicates that with the prevalence of COVID-19, several changes have transpired in areas of marketing, advertisements, promotional engagements and the media (Barro \& Weng, 2020). This has forced most big brands and businesses to re-strategise towards managing their current and future marketing or advertising need as a way of maintaining a steady inflow of income.

Whereas most brands are focused on striking the most appropriate tone in the coronavirus pandemic or healthy emergency, it is evident that the future portends market alteration, stiff competition and increased demand for different creative as well as aggressive marketing 
practices (Belzunegui-eraso, 2020). Fernandes (2020) indicates that as big brands adapt and figure out the most appropriate methods for marketing or promoting their services and products in the times of COVID-19, government institutions are fighting had to stop unfair business practices as a way of protecting the different vulnerable consumers and consequently eliminate different COVID-19 scams on local and international markets. Most businesses are continuously reevaluating most of their marketing and advertisement or promotional strategies (Burchell, 2011). In this case, most businesses are majorly focused on enhancing their advertisement and marketing levels mostly on online platforms since it is relatively hard to promote their products traditional marketing during the times of COVID-19.

\section{Methodology}

This study was based on survey data collected from a total of 150 participants that included 50 HRM experts and 100 marketing professionals. The data was collected using a well-designed survey questionnaire that was posted online for the different HRM experts and marketing professionals to provide their opinions concerning the impact of COVID-19 on human resource management and marketing. The reason for using these respondents was based on the fact that marketing professionals and HRM experts possess the best knowledge that can be based on establishing the current nature of the fields of marketing and human resource management as influenced by the different dynamics of COVID-19. The selected web users were included in the study upon their consent and willingness to answer the different questions about the topic of study. This, therefore, indicates that individual opinions of web users would play a significant role in ascertaining the current state of the fields of marketing and human resource management as influenced by the coronavirus pandemic as well as predicting the future of these fields in case this global pandemic persists. Additional data was collected from different secondary sources such as journals, textbooks, and government documents having information relating to the effects of the COVID-19 pandemic on the HRM practices as well as marketing in different organizations across the world.

Data analysis was done using SPSS. The results were presented in form of tables and charts and consequently interpreted based on frequencies and percentages. This method of presenting and interpreting results was applied for this survey since it helps to comprehensively explain the narratives and opinions of respondents towards giving a more conclusive response to the main research question of the study.

\section{Results}

The coronavirus global pandemic has greatly affected different essential sectors in most organizations across the world. Over $96 \%$ of the respondents confirmed that human resource management and marketing are the most affected sectors since the emergence of COVID-19 greatly changed the traditional working practices and marketing techniques as people were forced to start working remotely and use online platforms to market their products or services. However, a small section of respondents $(4 \%)$ did not agree with the narrative that HRM practices and future marketing have been greatly affected by COVID-19. 
Table 1. Whether HRM and future marketing practices are most affected by COVID-19

\begin{tabular}{|l|l|l|}
\hline Response & Frequency & Percentage (\%) \\
\hline Yes & $\mathbf{1 2 7}$ & $\mathbf{8 4 . 7}$ \\
\hline No & 23 & 415.3 \\
\hline Total & 150 & 100.0 \\
\hline
\end{tabular}

Source: Survey data 2020.

Concerning the ways through which COVID-19 has affected human resource management, the majority of respondents $(36 \%)$ as presented in figure 1 indicated that the pandemic has increased remote working, $14 \%$ indicated that COVID-19 has increased employee layoffs and led to disruptions in the normal working practices respectively, whereas the least number of respondents $(11 \%)$ indicated disruptions in the normal communication mechanisms. However, $13 \%$ of the respondents suggested opinions such as increased hiring of new employees, reduction in salaries of workers, deterioration in the individual wellbeing of employees, increase in agility, flexibility or creativity of HR professionals, and reduced commitment to different organizational activities while operating from home, among other opinions.

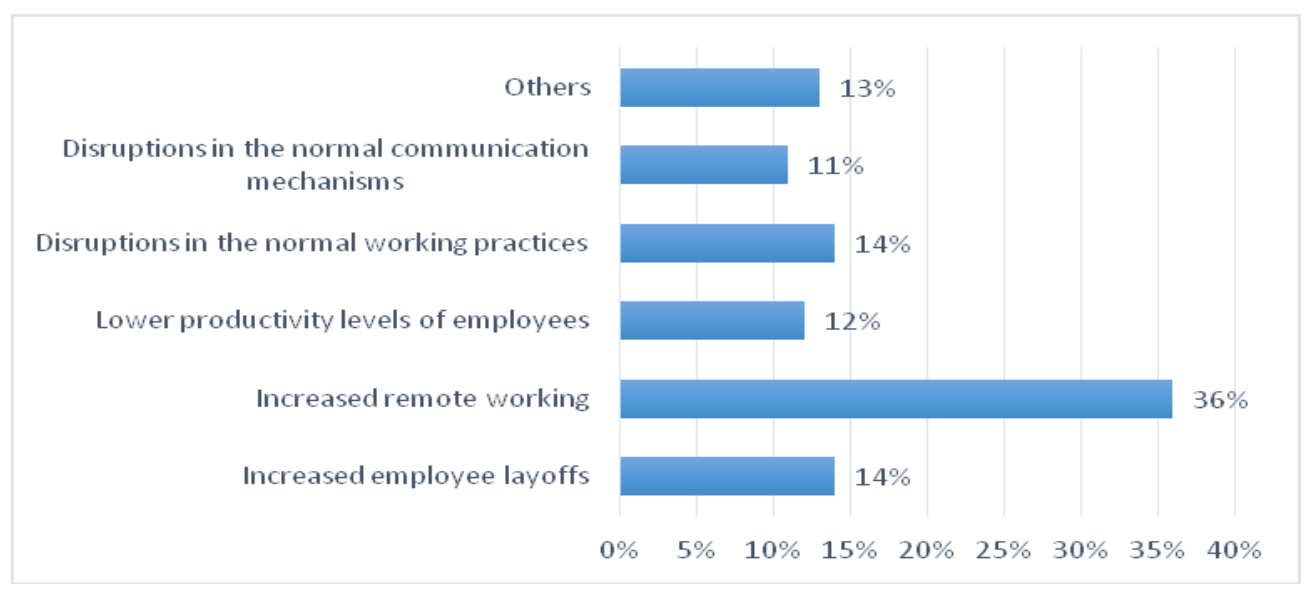

Figure 1. How COVID-19 has affected the field of human resource management

Survey data (2020).

The study was also aimed at establishing the relationship between COVID-19 and the HRM practices of organizations. To establish this relationship, a cross-tabulation of the responses on the influence of COVID 19 on organizations' or individual activities and the effect of COVID-19 on HRM practices was conducted and the correlational analysis was then conducted to establish the level of the relationship. The results obtained and the subsequent Pearson's coefficient values are presented in Table 2 . 


\section{Macrothink}

Table 2. Correlation between COVID-19 and HRM practices

\begin{tabular}{|l|l|r|r|}
\hline & & COVID-19 & \multicolumn{1}{|c|}{ HRM practices } \\
\hline COVID-19 & Pearson Correlation & 1 & $.417^{* *}$ \\
\cline { 3 - 4 } & Sig. (2-tailed) & & .000 \\
\cline { 3 - 4 } & $\mathrm{N}$ & $.417^{* *}$ & 150 \\
\hline HRM practices & Pearson Correlation & .000 & 1 \\
\cline { 2 - 4 } & Sig. (2-tailed) & 150 & 150 \\
\cline { 3 - 4 } & $\mathrm{N}$ & & \\
\cline { 3 - 4 } & &
\end{tabular}

**. Correlation is significant at the 0.01 level (2-tailed).

After the cross-tabulation and analysis, it was established that there is a significant relationship between COVID-19 and future marketing $\left(r=0.417^{* *}, n=150, p=.000\right)$. The results clearly show that COVID-19 have had a great impact on HRM practices which leads to acceptance of the null hypothesis $\mathrm{H}_{1}$ that there is a significant relationship between COVID-19 and HRM practices.

Concerning COVID-19's effect on future marketing, the majority of respondents (39\%) indicated a reduced physical contact with customers, $25 \%$ indicated increased use of online marketing platforms, $16 \%$ were for reduced costs of operation in marketing, while the least number of respondents (9\%) were for increased bargaining power of suppliers. $11 \%$ of the participants gave other opinions such as reduction in the number of customers, reduction in total sales, i9ncrease in and online viewership for online marketing websites, among other opinions.

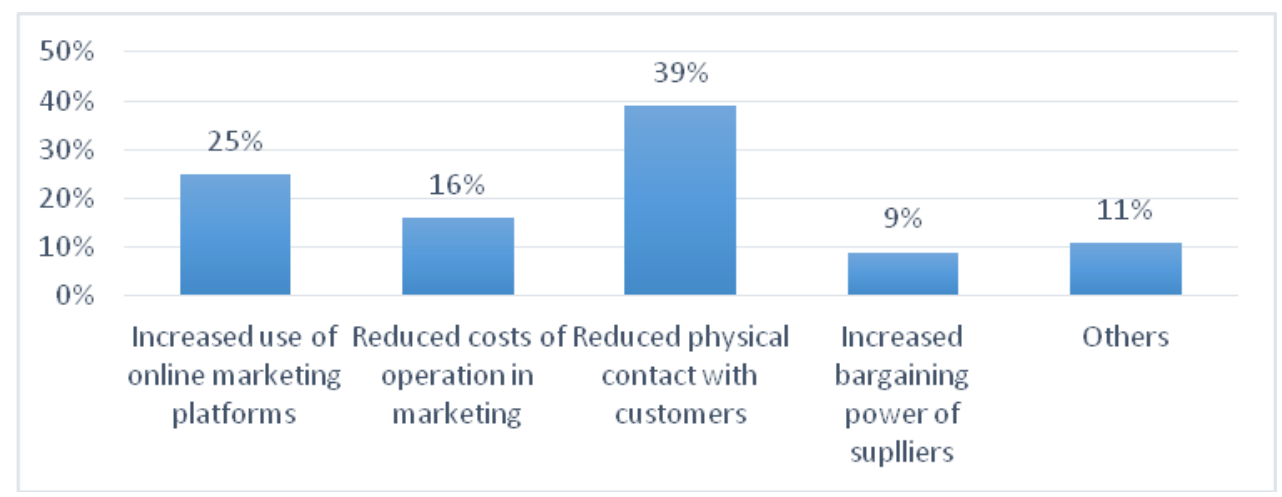

Figure 2. How COVID-19 has affected future marketing in different organizations

Source: Survey data (2020).

The study was also meant to establish a relationship between COVID-19 and future marketing. In this case, Pearson's rank correlation-based analysis was conducted to establish this relationship and this would then help in confirming the overall impact of COVID-19 on future marketing 
practices. The results obtained and the subsequent Pearson's coefficient values are presented in Table 3.

Table 3. Correlation between COVID-19 and future marketing

\begin{tabular}{|l|l|r|r|}
\hline & & \multicolumn{1}{|c|}{ COVID-19 } & \multicolumn{1}{|c|}{ Future marketing } \\
\hline COVID-19 & Pearson Correlation & 1 & $.426^{* *}$ \\
\cline { 2 - 4 } & Sig. (2-tailed) & & .000 \\
\cline { 3 - 4 } & $\mathrm{N}$ & 150 & 150 \\
\hline Future marketing & Pearson Correlation & $.426^{* *}$ & 1 \\
\cline { 2 - 4 } & Sig. (2-tailed) & .000 & 150 \\
\cline { 3 - 4 } & $\mathrm{N}$ & 150 & \\
\cline { 3 - 4 } &
\end{tabular}

**. Correlation is significant at the 0.01 level (2-tailed).

Source: Primary Data (2019).

Following cross-tabulation and correlational analysis, it was established that there is a positive relationship between COVID-19 and future marketing $\left(r=0.426^{* *}, n=150, p=.000\right)$. The results clearly show that the different dynamics of COVID-19 have greatly influenced the nature of marketing and will have a great impact on future marketing practices. These results also led to the acceptance of the null hypothesis $\mathrm{H}_{2}$ that there is a significant relationship between COVID-19 and future marketing.

The study also focused on establishing the different ways through which businesses or organizations can cope with the new challenging times of COVID-19 most especially in the areas of HRM and marketing. In this case, the majority of respondents (50.7\%) selected adopting new forms of technology for marketing and HRM, 36\% selected employing new relevant workforce while the least number of respondents $(6 \%)$ selected laying off less important employees to lower costs of operations. However, $7.3 \%$ suggested other measures such as restructuring the organization or business to focus on other activities that are compatible with the current times and lowering the process of some products to attract more customers to buy online, among other suggestions.

Table 4. How organizations or businesses can address the challenges of COVID-19 in areas of HRM and marketing

\begin{tabular}{|l|c|c|}
\hline Measures & Frequency & Percentage (\%) \\
\hline Adopt new forms of technology for marketing and HRM & 76 & 50.7 \\
\hline Employ new relevant workforce & 54 & 36.0 \\
\hline Layoff less important employees to lower costs of operation & 9 & 6.0 \\
\hline Others & 11 & 7.3 \\
\hline Total & $\mathbf{1 5 0}$ & $\mathbf{1 0 0}$ \\
\hline
\end{tabular}

Source: Survey (2020). 


\section{Discussion}

The study shows a huge impact of COVID-19 pandemic on the different aspects of human resource management and future marketing. Whereas there is an increased debate about the impact of the coronavirus pandemic (COVID-19) on human resource management and marketing in different organizations across the world, most of the emerging opinions and perceptions from different experts are much associated with the observations or guidance that seek to explain what a 'new normal' might be in the times of COVID-19 (Kalogiannidis, Chatzitheodoridis, \& Kontsas, 2020). Most studies and responses from HRM experts reveal that the times of COVID-19 have brought about several implications that are both a challenge and an opportunity to embrace innovations of conducting organizational tasks or activities (Khudhair et al., 2020). Most HRM experts and individuals in the field of marketing confirm that new approaches such as remote working and online marketing have been embraced as a way of coping with the challenging and changing times as a result of coronavirus. With the increasing uncertainty around the world due to the lack of a vaccine or cure for coronavirus, most organizations have supported and encouraged their employees to use different online platforms or applications such as the zoom app to undertake different HRM and marketing tasks on behalf of their organizations. This to some extent has left some individuals jobless since multiple tasks can now be done remotely by a single individual as opposed to being done by several employees at the workplace (Ambrocio \& Juselius, 2020). While remote working has become and will continue to be a norm and a flexible way of working among most professionals, it is important to understand that this practice is associated with several implications on the traditional working and marketing practices.

The study revealed that there is a higher likelihood that the current changes in the HRM and marketing practices will spread out to all countries across the world because COVID-19 is a global pandemic and has impacted nearly every part of the world. From the different responses obtained from the HRM experts that participated in the survey, it is clear that although COVID-19 has affected very many areas or industries across the world, the field of human resource management has been affected most. This is because millions of workers have been laid off or encouraged to adopt working remotely which to a greater extent has affected has had severe implications on the affected personalities (Belzunegui-eraso, 2020). However, a section of respondents reveals that the pandemic has had a positive impact on their mode of operation. For example, most HRM experts from the ears of public relations or administration, finance and insurance as well as management, revealed that the dynamics of COVID-19 were positively impacting their operations.

Most participants confirm that they have found a lot of convenience in working remotely since it allows them to operate in a relatively free or flexible environment as compared to their actual workplaces. Furthermore, the study findings revealed that most professionals prefer working remotely since it enables them to reunite with their families and consequently strengthen their relationship ties with both their children, spouses, and other family members, which is always not possible with the normal working practice of operating from their actual workplaces. The findings also confirm that some sectors have engaged in more hiring processes to address the new changes brought about by the pandemic. Nevertheless, the 
findings revealed that most of the organizations have halted their hiring processes since most of the activities were halted by the increasing soared of COVID-19 across the world.

Whereas most participants indicated that there increased remote working, which is predicted to continue increasing in the future, most recent research shows that some organizations are continuously reviewing the effectiveness and sustainability of remote working and are yet to commit themselves to this style of work. Most organizations have not generated much review or sales by their employees working from home since there is limited supervision that tends to make the employees less committed thereby affecting productivity or general output from the employees (McKibbin \& Fernando, 2020). The literature shows that to some extent some organization are not yet conversant with the ways through which remote working operates and this has to a greater extent affected the productivity and performance of some employees and the organizations as a whole (Kalogiannidis, 2020). It is important to note that implementing remote working requires organizations to implement different new policies, strategies, procedures, regulations and systems that sometimes become hard to fulfil for some organizations.

\section{Limitations}

It was initially not easy to obtain the consent of the respondents as well as their willingness to participate in the study whereby some participants wanted a financial remuneration before responding to the questions, which resulted in time wastage. However, this was solved by the researcher convincing the potential participants through persuasive email messages explaining the relevance of the study and assuring the respondents of maximum confidentiality.

The sample size of the study was relatively small which could have affected the generalizability of results since it may not represent the opinions of HRM professionals or marketers in other parts of the world. However different statistical methods particularly Pearson's rank correlation was used to obtain more reliable and accurate results.

\section{Areas for Future Research}

The study majorly focused on exploring the ways through which COVID-19 has impacted the areas of HRM and marketing. Through this process, it was established that some benefits such as innovations in methods of work have been established during the period of COVID-19. The future researcher can therefore focus on establishing mechanisms through which organizations and individuals can capitalize on the positive side of COVID-19 to adopt to solve the different organizational challenges.

\section{Conclusion}

The general impact of the COVID-19 global pandemic on HRM practices and future marketing is an unfolding story that is greatly complex as well as fluid most especially in its ever-changing dimensions. One of the most significant impacts of the coronavirus pandemic is on the well-being of organizations and the general nature of traditional workplaces as well as the future marketing of different products and services offered by businesses or 
organizations. Even though the different long-term implications of coronavirus are uncertain, the pandemic will likely continue to greatly affect organizational life and future marketing initiatives in different organizations across the world. In this case, it recommended that organizations focus on forward-thinking, building on the major assumption that the main challenge being faced globally is not a singular, anomalous event, but is instead associated with a "new reality" that offers different new opportunities that all marketers, HR professions and all organizational scholars or practitioners must embrace to cope with the changing times.

\section{References}

Ambrocio, G., \& Juselius, M. (2020). Dealing with the costs of the COVID-19 pandemic what are the fiscal options?

Atkeson, A. (2020). what will be the economic impact of covid-19 in the us? Rough estimates of disease scenarios. NBER Working Paper No. w26867. https://doi.org/10.3386/w26867

Baert, S. et al. (2020). How Do We Think the COVID-19 Crisis Will Affect Our Careers (If Any Remain)?

Baldwin, R., \& Weder, B. (2020). Economics in the Time of COVID-19.

Barro, R. J., \& Weng, J. (2020). The coronavirus and the great influenza pandemic.

Belzunegui-eraso, A. (2020). Teleworking in the Context of the Covid-19 Crisis (pp. 1-18). https://doi.org/10.3390/su12093662

Burchell, J. (2011). Anticipating and Managing Resistance in Organizational Information Technology (It) Change Initiatives. International Journal of the Academic Business World, 5(1), 19-28.

Fernandes, N. (2020). Economic effects of coronavirus outbreak (COVID-19) on the world economy (pp. 1-32). https://doi.org/10.2139/ssrn.3557504

He, H., \& Harris, L. (2020). Since January 2020 Elsevier has created a COVID-19 resource centre with free information in English and Mandarin on the novel coronavirus COVID-19. The COVID-19 resource centre is hosted on Elsevier Connect, the company' s public news and information.

Inoue, H., \& Todo, Y. (2020). The propagation of the economic impact through supply chains: The case of a mega-city lockdown against the spread of COVID-19. https://doi.org/10.2139/ssrn.3564898

Kalogiannidis, S. (2020).Covid Impact on Small Business. International Journal of Social $\begin{array}{llll}\text { Science } \quad \text { Economics } & \text { 387vention, }\end{array}$ https://doi.org/10.23958/ijssei/vol06-i12/257

Kalogiannidis, S., \& Chatzitheodoridis, F. (2021). Impact of Covid-19 in the European Start-ups Business and the Idea to Re-energise the Economy. International Journal of Financial Research, 12(2), 55. https://doi.org/10.5430/ijfr.v12n2p55 
Kalogiannidis, S., Chatzitheodoridis, F., \& Kontsas, S. (2020). An Eclectic Discussion of the Effects of COVID-19 Pandemic on the World Economy During the First Stage of the Spread. $\begin{array}{lllll}\text { International Journal of Financial } & \text { Research, } & 11(6), & \end{array}$ https://doi.org/10.5430/ijfr.v11n6p137

Khudhair, H. Y. et al. (2020). The Impact of COVID-19 on Supply Chain and Human Resource Management Practices and Future Marketing. International Journal of Supply Chain Management, 9(5), 1681-1685.

Lauer, S. A. et al. (2020). O RIGINAL R ESEARCH The Incubation Period of Coronavirus Disease 2019 (COVID-19) From Publicly Reported Confirmed Cases: Estimation and Application. https://doi.org/10.7326/M20-0504

McKibbin, W. J., \& Fernando, R. (2020). The Global Macroeconomic Impacts of COVID-19: Seven Scenarios. SSRN Electronic Journal. https://doi.org/10.2139/ssrn.3547729

Stavros, K., Melfou, K., \& Papaevangelou, O. (2020). Global Marketing Strategic Approaches on Multi National Companies Product Development. International Journal of Scientific Research and Management, 8(12), 2084-2090. https://doi.org/10.18535/ijsrm/v8i12.em08

\section{Appendix}

\section{Questionnaire}

QTN 1. Are human resource management and marketing the most effected sectors since the emergence of COVID-19

1. Yes

2. No

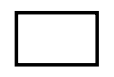

QTN 2. COVID-19 has affected the wellbeing of organizations and individuals

1. Agree

2. Disagree

QTN 2. How has COVID-19 affected the field of human resource management?

1. Increased employee layoffs

2. Increased remote working

3. Lower productivity levels of employees

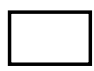

4. Disruptions in the normal working practices

5. Disruptions in the normal communication mechanisms

6. Others

QTN 3. How has COVID-19 affected future marketing in different organizations?

1. Increased use of online marketing platforms

2. Reduced costs of operation in marketing 
3. Reduced physical contact with customers

4. Increased bargaining power of suppliers

5. Others

QTN 4. How can organizations or businesses address the challenges of COVID-19 in areas of HRM and marketing?

1. Adopt new forms of technology for marketing and HRM

2. Employ new relevant workforce

3. Layoff less important employees to lower cost of operation

4. Others

\section{Copyright Disclaimer}

Copyright for this article is retained by the author(s), with first publication rights granted to the journal.

This is an open-access article distributed under the terms and conditions of the Creative Commons Attribution license (http://creativecommons.org/licenses/by/3.0/). 